\title{
Erratum to: Author's reply to comments on Shyam et al.: Leg lengthening by distraction osteogenesis using the Ilizarov apparatus: a novel concept of tibia callus subsidence and its influencing factors
}

Hae-Ryong Song • Ashok K. Shyam

Published online: 8 April 2010

(C) Springer-Verlag 2010

Erratum to: International Orthopaedics (SICOT)

DOI 10.1007/s00264-010-0982-z

Due to an oversight in manuscript preparation, the name of the second author, Ashok K. Shyam, was omitted. The missing information is supplied here.

The online version of the original article can be found at http://dx.doi. org/10.1007/s00264-010-0982-z.

H.-R. Song $(\bowtie)$

Department of Orthopaedic Surgery,

Korea University Medical Center Guro Hospital,

Seoul, Korea

e-mail: songhae@korea.ac.kr

A. K. Shyam

Sancheti Institute for Orthopaedics and Rehabilitation,

16, Shivaji nagar,

Pune 411005 Maharashtra, India 